ARTIGO ORIGINAL

\title{
DIAGNÓSTICO PARASITOLÓGICO E MOLECULAR DA BABESIOSE CANINA NA CIDADE DE GOIÂNIA-GO
}

\author{
Sabrina Castilho Duarte, ${ }^{1}$ Carla Cristina Braz Louly, ${ }^{1}$ Osvaldo José da Silveira \\ Neto, ${ }^{2}$ Tatiana Nunes de Azevedo Romanowski, ${ }^{3}$ Ruy de Souza Lino Junior ${ }^{4}$ e \\ Guido Fontgalland Coelho Linhares ${ }^{5}$
}

\section{RESUMO}

\begin{abstract}
A babesiose canina é uma enfermidade causada por hematozoários intraeritrocitários obrigatórios do gênero Babesia. As espécies Babesia canis e Babesia gibsoni apresentam ampla distribuição geográfica. Mundialmente são reconhecidas três subéspecies de $B$. canis: $B$. canis canis, $B$. canis vogeli e $B$. canis rossi. A caracterização morfológica observada no exame direto de esfregaços sangüíneos permite a diferenciação entre $B$. canis e $B$. gibsoni, mas não entre as subespécies de $B$. canis. B. gibsoni é um parasito pequeno, normalmente encontrado em formas isoladas no interior das hemácias. $B$. canis é um parasito do grupo das grandes babesias, que geralmente se apresenta aos pares. O objetivo deste trabalho foi identificar, por meio de estudos morfológicos e moleculares, as espécies e subespécies de Babesia envolvidas nos casos clínicos de babesiose canina na cidade de Goiânia. Amostras de sangue foram colhidas para a preparação de esfregaços sangüíneos e apenas as amostras positivas foram encaminhadas para a extração de DNA, totalizando 30 amostras. A avaliação microscópica dos esfregaços revelou formas intra-eritrocitárias variadas de trofozoítos e merozoítos e, em algumas amostras, prevaleceram formas com valores próximos a B. gibsoni; em outras, formas equivalentes a $B$. canis. O diagnóstico subespécie-específico por PCR confirmou a identidade molecular de B. c. vogeli nas 30 amostras avaliadas. Dessa forma foi possível concluir que, apesar das diferenças morfométricas verificadas entre as amostras procedentes da cidade de Goiânia, todas foram identificadas como subespécie B. c. vogeli.
\end{abstract}

DESCRITORES: Babesiose. Cão. Babesia. Hemoparasito. PCR.

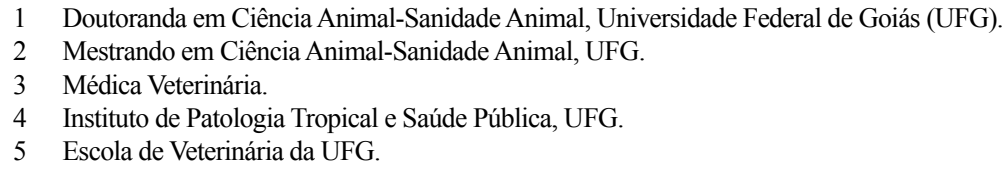

Endereço para correspondência: Laboratório de Doenças Parasitárias, Escola de Veterinária da UFG, Campus II Caixa postal 131 CEP: 74001-970, Goiânia, GO, Brasil. E-mail: sabrinacd@gmail.com

Recebido para publicação em: 15/5/2008. Revisto em: 1/9/2008. Aceito em: 5/9/2008. 


\section{INTRODUÇÃO}

Babesiose é uma enfermidade causada por protozoários do gênero Babesia, clinicamente caracterizada por febre, anemia e hemoglobinúria (Camacho et al., 2001).

São conhecidas duas espécies do gênero Babesia capazes de provocar infecção natural em cães, a $B$. gibsoni e a $B$. canis. Esta última é classificada em três subespécies: B. canis rossi, B. canis canis e B. canis vogeli (Kuttler, 1988, Uilenberg et al., 1989).

A B. gibsoni tem sido encontrada na Ásia, América do Norte, norte e leste da África (Kjemtrup et al., 2000), Europa (Casapulla et al., 1998) e, recentemente, no Brasil (Trapp et al., 2006).

As subespécies de B. canis ocorrem em diferentes regiões: B. c. rossi é encontrada no sul da África (Uilenberg et al., 1989) e no Sudão (Oyamada et al., 2005); B. c. canis é encontrada na Europa (Uilenberg et al., 1989; Caccio et al., 2002, Fornelio et al., 2003, Foldvari et al., 2005) e B. c. vogeli, no norte e sul da África (Matjila et al., 2004), na América do Norte (Uilenberg et al., 1989), na Europa (Caccio et al., 2002, Fornelio et al., 2003), na Austrália (Jefferies et al., 2003), no Sudão (Oyamada et al., 2005), na Turquia (Gulanber et al., 2006) e no Brasil (Passos et al., 2005, Duarte et al., 2008).

Alguns autores adotam um sistema de classificação que eleva as subespécies de B. canis ao status de espécies: B. canis, B. vogeli e B. rossi. Apesar das diferenças genéticas, antigênicas (Carret et al., 1999) e sorológicas (Uilenberg et al., 1989), observadas nos diferentes isolados regionais destes organismos, ainda não existe estudo definitivo sobre sua sistemática.

O exame microscópico direto do esfregaço sangüíneo é o método convencionalmente empregado para o diagnóstico diferencial entre $B$. canis e B. gibsoni, tendo como base as características morfométricas de referência para cada espécie (Kjemtrup et al., 2000). Essa técnica não permite a diferenciação entre subespécies, para isso tem sido aplicada metodologia com base em biologia molecular (Carret et al., 1999, Duarte et al., 2008).

A B. gibsoni é um parasito pequeno, com tamanho de $1,0 \mu \mathrm{m} \times 3,2 \mu \mathrm{m}$, normalmente encontrado em formas isoladas no interior das hemácias. $B$. canis por sua vez, é um parasito do grupo das grandes babesias, mede em torno de $2,4 \mu \mathrm{m} \times 5,0$ $\mu \mathrm{m}$ e geralmente se apresenta aos pares no interior das hemácias (Hoskins, 1991).

Além da morfologia e patogenicidade para o hospedeiro vertebrado, existe ainda a diferenciação pela adaptação às espécies de vetores potencialmente capazes de atuar na transmissão. A B. gibsoni é transmitida pelos carrapatos Haemaphysalis bispinosa e Rhipicephalus sanguineus e a Babesia canis pelo $R$. sanguineus, Dermacentor reticulatus e Haemaphysalis leachi. Alguns autores reportaram ainda a transmissão experimental de B. canis por Dermacentor andersoni e Hyalomma marginatum (Hoskins, 1991). 
Dentre as subespécies de B. canis, a B. c. rossi é transmitida pelo carrapato $H$. leachi e causa infecção muitas vezes fatal, o que caracteriza sua elevada patogenicidade. B. c. vogeli é transmitida pelo $R$. sanguineus e determina infecções moderadas. A B. c. canis é transmitida pelo D. reticulatus e apresenta a menor patogenicidade entre as demais sub-espécies (Uilenberg et al, 1989).

Em relação à Região Centro-Oeste não existem referências na literatura sobre a etiologia da babesiose canina ao nível de espécies e subespécies. Na cidade de Goiânia é freqüente a ocorrência de cães doentes por enfermidades determinadas por hemoparasitos e a babesiose ocupa posição de destaque nesta casuística.

O objetivo deste trabalho foi esclarecer, com o emprego de técnicas parasitológicas convencionais e moleculares, a participação das espécies e subespécies envolvidas com a babesiose canina em cães de Goiânia e, dessa forma, contribuir para melhor compreensão de sua epidemiologia no país.

\section{METODOLOGIA}

Dos cães atendidos para consulta no Hospital Veterinário da Escola de Veterinária da Universidade Federal de Goiás (EV/UFG), de 26 de janeiro a 12 de dezembro de 2006, e que apresentavam sinais clínicos sugestivos de hemoparasitose, foram colhidas amostras de sangue com EDTA (Anticoagulante Universal, Doles, Goiânia) para a realização de exames hematológicos.

As amostras foram todas utilizadas para o preparo de esfregaços sangüíneos visando a pesquisa e à identificação de formas intra-eritrocitárias de organismos babesídeos, conforme Hoskins (1991). Os esfregaços foram preparados em lâminas de microscopia, fixados pelo metanol e corados por 30 minutos em solução de Giemsa (Merck), diluído em tampão Sorensen, segundo Correa \& Correa (1992).

Os parasitos foram identificados conforme as características morfométricas descritas para o gênero Babesia e mais especificamente para as espécies $B$. canis e B. gibsoni (Shortt, 1973; Hoskins, 1991). Desta forma, no período de realização do estudo, foram identificados um total de 30 isolados de Babesia spp.

As imagens das formas parasitárias sangüíneas foram capturadas e documentadas em câmara digital (Sony DSC - S85 Cyber-shot) acoplada a fotomicroscópio (Axiostar plus - Zeiss). Para a morfometria foi utilizado o programa Image J 1.37v (National Institutes of Health, USA) calibrado especificamente para o microscópio utilizado para capturar as imagens (Objetiva 100X, distância em pixels de 688 e $50 \mu \mathrm{m}$ ). As medidas obtidas foram classificadas em tabela de Excel para obtenção dos valores de média das amostras. Foram tomadas medidas separadamente dos merozoítos e trofozoítos de Babesia, as quais foram analisadas pelo software para caracterização morfométrica. Estruturas amorfas ou atípicas não foram incluídas nessa avaliação.

Paralelamente a essa avaliação, as amostras de sangue dos isolados foram submetidas ao processo de extração de DNA para a execução do diagnóstico molecular 
pela técnica de PCR, conforme metodologia descrita por Duarte et al. (2008) para as subespécies de B. c. vogeli, B. c. canis e B. c. rossi. Os testes de PCR para B. gibsoni foram realizados empregando-se iniciadores e protocolo, segundo Inokuma et al. (2004) e, para B. equi, os iniciadores e protocolo descritos por Bashiruddin et al. (1999).

Como controle de especificidade foram utilizadas amostras de referência do DNA genômico de B. c. canis, B. c. vogeli, B. c. rossi e B. gibsoni (procedentes do Instituto de Parasitologia Comparada e Medicina Tropical da Universidade Ludwig Maximilian da Alemanha), B. equi (UNESP de Jaboticabal), E. canis, $H$. canis e M. haemocanis (banco de DNA genômico de hemoparasitos do Laboratório de Diagnóstico de Doenças Parasitárias da EV/UFG).

\section{RESULTADOS E DISCUSSÃO}

O estudo morfométrico das formas parasitárias presentes nos esfregaços sangüíneos dos 30 isolados revelou dimensões que variaram entre $1,01 \mu \mathrm{m}$ a $2,87 \mu \mathrm{m}$ para a largura e entre $1,67 \mu \mathrm{m}$ a $4,82 \mu \mathrm{m}$ para o comprimento. Tomando-se por base os valores morfométricos de referência para as espécies $B$. gibsoni $(1,0 \mu \mathrm{m} \times 3,2 \mu \mathrm{m})$ e $B$. canis $(2,4 \times 5,0 \mu \mathrm{m})$, considerados por Hoskins (1991), observou-se que os valores médios encontrados para a maioria dos isolados, tanto para a largura quanto para o comprimento, foram próximas ou superiores às medidas de referência para B. gibsoni e inferiores às de $B$. canis (Figura 1).

Apesar da maior semelhança dos isolados com a espécie B. canis, algumas formas avaliadas nos esfregaços demonstraram dimensões dentro dos parâmetros atribuídos à $B$. gibsoni. $\mathrm{O}$ isolado $\mathrm{n}^{\circ} 17$ apresentou hemácias infectadas com formas parasitárias únicas, com medidas variando de 1,24-2,4 x 2,90-3,0 $\mu \mathrm{m}$, valores próximos aos atribuídos a $B$. gibsoni de acordo com Hoskins (1991). Se a avaliação fosse feita com base apenas nesse parâmetro, poderia levar a interpretações equivocadas quanto à espécie de Babesia observada.

$\mathrm{Na}$ avaliação microscópica dos esfregaços, foram observadas formas intra-eritrocitárias variadas de trofozoítos e merozoítos e, em alguns isolados, prevaleceram formas pequenas e em outros, formas grandes (Figura 1).

A questão que envolve o pleomorfismo de $B$. canis encontra-se bem documentada na literatura (Shortt, 1973). Birkenheuer et al. (2004) relataram variações morfométricas no tamanho de merozoítos, de $2 \mu \mathrm{m} \times 3,3 \mu \mathrm{m}$ até $5 \mu \mathrm{m} \times$ $6 \mu \mathrm{m}$, com média de $2,3 \mu \mathrm{m} \times 4 \mu \mathrm{m}$.

A maioria dos isolados utilizados neste estudo apresentou outras características morfológicas semelhantes às atribuídas a $B$. canis como, por exemplo, formas piriformes dos merozoítos, formando um ou mais pares intra-eritrocitários, conforme documentado por Kuttler (1988) e Hoskins (1991). Quanto aos trofozoítos, estes também foram caracterizados como estruturas arredondadas maiores, às vezes, ovais, alongados ou amebóides, como descrito por Shortt (1973) para a espécie B. canis. 


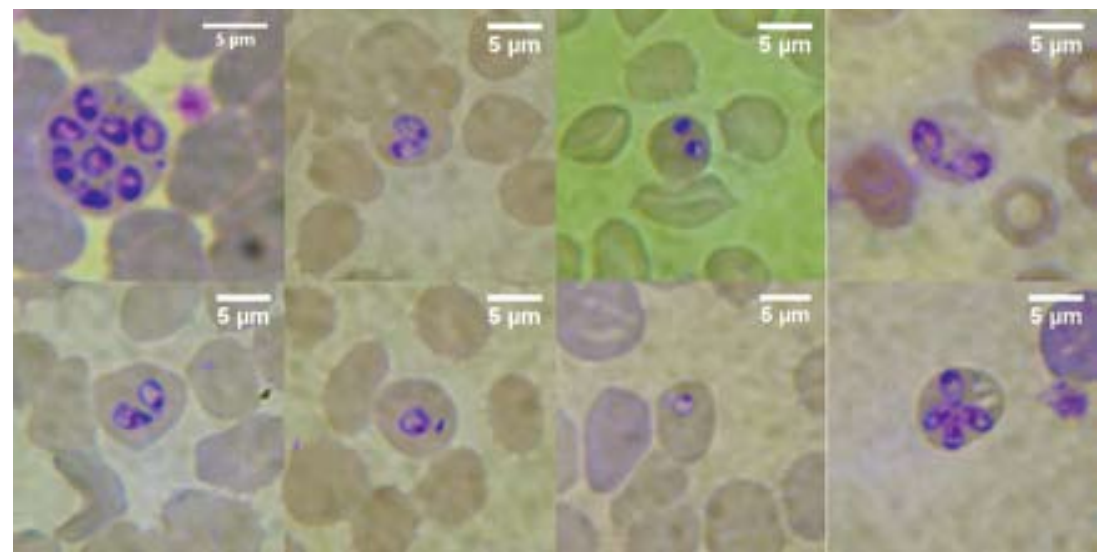

Figura 1. Formas intra-eritrocíticas de Babesia sp. observadas nos isolados obtidos de cães anêmicos, procedentes da cidade de Goiânia, Goiás.

A babesiose canina é, geralmente, atribuída a organismos do grupo das grandes (B. canis) ou pequenas (B. gibsoni) babesias. Na rotina, o diagnóstico laboratorial fundamenta-se na avaliação do tamanho e morfologia das formas intra-eritrocíticas. Entretanto, como a situação que envolve a taxonomia das espécies de Babesia de origem canina não se encontra totalmente definida, o diagnóstico definitivo com base nesses critérios pode ser questionado (Passos et al., 2005). Trabalhos recentes têm demonstrando a infecção de cães por outras espécies pequenas como B. equi (Fornelio et al., 2004), B. microti-like (Zahler et al., 2000; Camacho et al., 2001), B. conradae (Kjemtrup \& Conrad., 2006), e também, possivelmente, uma nova espécie do grupo das grandes babésias (Birkenheuer et al., 2004).

Essa situação tem motivado, cada vez mais, o uso, de técnicas de biologia molecular em estudos que envolvem a etiologia e a epidemiologia da babesiose canina. No primeiro estudo em nível molecular, realizado no Brasil, Passos et al. (2005) comprovaram a identidade de cinco isolados como a subespécie B. $c$. vogeli, os quais apresentavam formas intra-eritrocitárias $>2,5 \mu \mathrm{m}$. Esse trabalho foi realizado com quatro amostras oriundas do estado de Minas Gerais e uma amostra proveniente de um cão do estado de São Paulo. De Sá et al (2006) realizaram estudo com RFLP-PCR em amostras do Rio de Janeiro, por meio do qual também puderam confirmar a presença da sub-espécie B. c. vogeli. Recentemente, Trapp et al (2006) encontraram, por meio da amplificação do gene SSU RNAr e análise por sequenciamento, a espécie $B$. gibsoni no Brasil, que até então só havia sido relatada por identificação morfológica por Braccini et al. (1992).

No presente estudo, o diagnóstico molecular permitiu a identificação conclusiva sobre o agente etiológico de cada isolado, ao contrário do método de identificação morfométrica que não é apropriado para o diagnóstico em nível de 
subespécie e muitas vezes inconclusivo, até mesmo para a diferenciação entre as espécies de Babesia.

O diagnóstico subespécie-específico por PCR confirmou a identidade molecular de B. c. vogeli em todas as 30 amostras avaliadas neste estudo (Figura 2). Os resultados dos testes de PCR para as subespécies B. c. canis e B. c. rossi, assim como para as espécies $B$. gibsoni e $B$. equi foram todos negativos para as 30 amostras avaliadas.

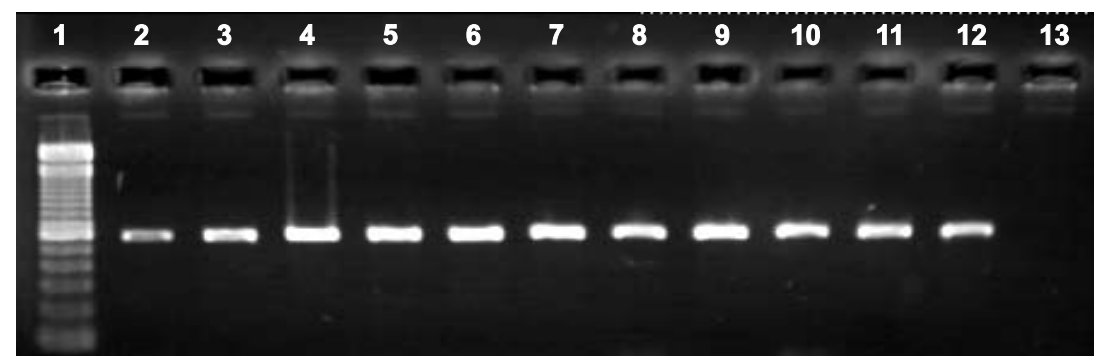

Figura 2. Eletroforese dos isolados obtidos de cães anêmicos, procedentes da cidade de Goiânia, Goiás. Produtos de $590 \mathrm{pb}$ de B. c. vogeli obtidos pela PCR. 1- marcador de 100pb; 2 a 11:isolados de números 1 a 10; 12: controle positivo; 13: controle negativo.

\section{CONCLUSÃO}

O diagnóstico parasitológico realizado em algumas amostras foi inconclusivo para identificar a espécie de Babesia envolvida na infecção em cães da cidade de Goiânia. O diagnóstico molecular possibilitou a identificação exclusiva da subespécie $B$. c. vogeli em cães procedentes da cidade de Goiânia, apesar das diferenças morfométricas verificadas no exame parasitológico.

\section{AGRADECIMENTOS:}

Esse trabalho contou com o suporte financeiro da CAPES (Coordenação de Aperfeiçoamento de Ensino Superior).

\section{ABSTRACT}

Parasitologic and molecular diagnosis of canine babesiosis in Goiânia, Brazil

Canine babesiosis is a disease caused by protozoans of the genus Babesia. The species Babesia canis and Babesia gibsoni are spread all around the world. Babesia canis is classified into three subspecies: B. canis canis, B. canis vogeli 
and $B$. canis rossi. The identification of individual species has traditionally been based on the morphologic features of the intraerythrocytic forms. B. canis, a large piroplasm $(4-5 \mu \mathrm{m})$ which usually occurs as a single pear-shaped piroplasm or pairs of merozoítes that divides through binary fission within the erythrocyte, and $B$. gibsoni, a small parasite that commonly appears as individual ring forms or piriform bodies sized between 1 and $2.5 \mu \mathrm{m}$. This identification method cannot be used to morphologically distinguish among the $B$. canis subspecies. The objective of the present study was to identify the species and subspecies of the Babesia organisms involved with infections of dogs living in the city of Goiânia, state of Goiás, Brazil, by using morphological and molecular techniques. Blood samples were obtained from dogs presenting hemoparasitosis-like clinical signs and submitted to blood smear. Samples that tested positive were then submitted to DNA extraction (30 samples, total). The microscopic examination has shown varied forms of trophozoites and merozoites. Some samples presented intraeritrocytic bodies with morphological features that most resembled $B$. gibsoni and other equivalent forms of $B$. canis. The subspecies-specific diagnosis by PCR confirmed the molecular identity of $B . C$. vogeli in the 30 samples. In conclusion, the results indicate that the subspecies $B . C$. vogeli is well spread in naturally infected dogs from the city of Goiânia, in spite of some morphologic differences observed among specimens.

KEY WORDS: Babesiosis. Dog. Babesia. Hemoparasite. PCR.

\section{REFERÊNCIAS}

1. Bashiruddin JB, Cammàb C, Rebêlo E. Molecular detection of Babesia equi and Babesia caballi in horse blood by PCR amplification of part of the 16S rRNA gene. Vet Parasitol 84: 75-83, 1999.

2. Birkenheuer AJ, Neel J, Ruslander D, Levy, MG, Breitschwerdt EB. Detection and molecular characterization of a novel large Babesia species in a dog. Vet Parasitol 124: 151-160, 2004.

3. Braccini GL, Chaplin, EL, Stobbe, NS, Araujo, FAP, Santos, NR. Protozoology and rickettsial findings of the laboratory of the veterinary faculty of the Federal University of Rio Grande do Sul, Brazil, 1986 - 1990. Arq Fac Vet UFRGS 20: 134-149, 1992.

4. Caccio SM, Antunovic B, Moretti A, Mangili A, Marinculic A, Baric RR, Slemenda SB, Pieniazek NJ. Molecular characterization of Babesia canis canis and Babesia canis vogeli from naturally infected European dogs. Vet Parasitol 106: 285-292, 2002.

5. Camacho AT; Pallas E, Gestal JJ.; Guitián FJ, Olmeda AS, Goethert HK, Telford SR. Infection of dogs in north-west Spain with a Babesia microti-like agent. Vet Rec 3: 552-555, 2001.

6. Carret C, Walas F, Carey B, Grande N, Precigout E, Moubri K, Schetters TP, Gorenflot A. Babesia canis canis, Babesia canis vogeli, Babesia canis rossi: differentiation of the three subspecies by a restriction fragment length polymorphism analysis on amplified small subunit ribosomal RNA genes. J Euc Microbiol 46: 298-303, 1999.

7. Casapulla RL, Baldi V, Avallone R, Sannino L, Pazzanese L, Mizzoni V. Canine piroplasmosis due to Babesia gibsoni: clinical and morphological aspects. Vet Rec 142: 168-169, 1998.

8. Correa WM, Correa CNM. Enfermidades infecciosas dos mamiferos domésticos. $2^{\circ}$ edição. Ed Medsi, Rio de Janeiro, 1992. 843 p.

9. De Sá AG, Cerqueira AMF, O'dwyer LH, Macieira DB, Abreu, FS, Ferreira RF, Pereira AM, Velho PB, Almosny NRP. Detection and molecular characterization of Babesia canis vogeli from naturally infected Brazilian dogs. Int J App Res Vet Med 4: 163-168, 2006. 
10. Duarte SC, Linhares GFC, Romanowski TN, Neto, OJS, Borges LMF. Assessment of primers designed for the subspecies-specific discrimination among Babesia canis canis, Babesia canis vogeli and Babesia canis rossi by PCR assay. Vet Parasitol 152: 16-20, 2008.

11. Foldvari G; Hell E, Farkas R. Babesia canis canis in dogs from Hungary: detection by PCR and sequencing. Vet Parasitol 127: 221-226, 2005.

12. Fornelio AC, Marcos AM, Sarana, AB, Carretero, JCB. Molecular studies on Babesia, Theileria and Hepatozoon in Southern Europe. Part I. Epizootiological aspects. Vet Parasitol 113: 189-201, 2003.

13. Fornelio AC, Gonzales MAR, Sarana AB, Carretero JCB. The expanding universe of piroplasms. Vet Parasitol 119: 337-345, 2004.

14. Gülanber A, Gorenflot A, Schetters TPM, Carcy B. First molecular diagnosis of Babesia vogeli in domestic dogs from Turkey. Vet Parasitol 139: 224-230, 2006.

15. Hoskins JD. Veterinary clinics of North America. Ed Saunders Company, Philadelphia, 1991. $201 \mathrm{p}$.

16. Inokuma H, Yoshizaki Y, Matsumoto K, Okuda M, Onishi T, Nakagome K, Kosugi R, Hirakawa M. Molecular survey of Babesia infection in dogs in Okinawa, Japan. Vet Parasitol 121: 341-346, 2004.

17. Jefferies R, Ryan UM, Muhinickel CJ, Irwint PJ. Two species of canine Babesia in Australia: detection and characterization by PCR. J Parasitol 89: 409-412, 2003.

18. Kjemtrup AM, Kocan AA, Whitworth L, Meinkoth J, Birkenheuer AJ, Cummings J, Boudreaux MK, Stockham SL, Irizarry-Rovira A, Conrad PA. There are least three genetically distinct small piroplasms from dogs. Int J Parasitol 30: 1501-1505, 2000.

19. Kjemtrup AM, Conrad PA. A review of the small canine piroplasms from California: Babesia conradae in the literature. Vet Parasitol 138: 112-117. 2006.

20. Kuttler KL. World-wide impact of babesiosis. In: Ristic M. Babesiosis of domestic animals and man . CRC Press, Boca Raton, 1988. 22p.

21. Matjila PT, Penzhorn BL, Bekker CPJ, Nijhof AM, Jongejan F. Confirmation of occurrence of Babesia canis vogeli in domestic dogs in South Africa. Vet Parasitol 122: 119-125, 2004.

22. Oyamada M, Davoust B, Boni M, Dereure J, Bucheton B, Hammad A, Itamoto K, Okuda M, Inokuma $\mathrm{H}$. Detection of Babesia canis rossi, B. canis vogeli, and Hepatozoon canis in Dogs in a Village of Eastern Sudan by using a screening PCR and sequencing methodologies. Cl Diag Lab Immunol 12: 1343-1346, 2005.

23. Passos LMF, Geiger SM, Ribeiro MFB, Pfister K, Zahler-Rinder M. First molecular detection of Babesia vogeli in dogs from Brazil. Vet Parasitol 127: 81-85, 2005.

24. Shortt HE. Babesia canis: The life cycle and laboratory maintenance in its arthropod and mammalian hosts. Int J Parasitol 3: 119-148, 1973.

25. Trapp SM, Messick JB, Vidotto O, Jojima FS, Morais HSA. Babesia gibsoni genotype Ásia in dogs from Brazil. Vet Parasitol 141: 177-180, 2006.

26. Uilenberg G, Franssen FFJ, Perié NM. Three groups of Babesia canis distinguished and a proposal for nomenclature. Vet Quart 1: 33-40, 1989.

27. Zahler M, Schein E, Rinder H, Gothe R. Detection of a new pathogenic Babesia microti-like species in dogs. Vet Parasitol 89: 241-248, 2000. 